\title{
Uma Nota Sobre Amortização de Dívidas e Prestações Constantes
}

\author{
Clovis de Faro*
}

\author{
Conteúdo: 1. Introdução; 2. Estrutura Analítica; 3. o Caso do Regime de Juros Compostos \\ (Tabela Price); 4. 0 Caso do Regime de Juros Simples; 5. Conclusão. \\ Palavras-chave: Amortização de Dívidas, Tabela Price, Juros Simples. \\ Códigos JEL: $\quad$ E4, E5.
}

Com base no entendimento da presença de anatocismo no emprego da Tabela Price, tem sido proposto, inclusive judicialmente, que se faça uso do regime de juros simples na amortização de dívidas. Focando no caso de prestações constantes, como no caso da Tabela Price, é evidenciado que o emprego de juros simples, inclusive no chamado "método de Gauss", resulta em inconsistências financeiras.

Believing that the constant payments system of debt amortization, which is known in Brazil as Tabela Price, necessarily provokes capitalization of accrued interest, there have been judicial sentences stipulating the adoption of simple interest. It is shown that the use of simple interest schemes, including the so called "method of Gauss", leads to financial inconsistencies.

\section{INTRODUÇÃO}

Indubitavelmente, inclusive em escala planetária, o sistema de amortização de dívidas mais frequentemente utilizado é o que se baseia no pagamento de prestações constantes.

Em especial, aqui no Brasil, mormente no caso de financiamentos habitacionais, que costumam ser de longo prazo, e mesmo para aquisição de bens duráveis, geralmente operações de curto a médio prazo, o esquema de prestações constantes é o mais popular. Sendo que, no âmbito do sistema Financeiro de Habitação, é dito ser segundo a Tabela Price. ${ }^{1}$

Entretanto, por ser fundamentada no regime de juros compostos, a adoção da Tabela Price tem sido fulcro de repetidos questionamentos em nosso judiciário (veja-se, por exemplo, de Faro e Guerra 2009). Isso porque, a meu ver equivocadamente, associa-se ao regime de juros compostos o que, no jargão jurídico, se denomina de anatocismo (que, segundo Houaiss (2001), significa cobrança de juros sobre juros). Todavia, como formalmente discutido em de Faro (2013b), muito embora anatocismo só ocorra no regime de juros compostos, a adoção deste regime de juros não implica, necessariamente, na

\footnotetext{
*Professor da Escola Brasileira de Economia e Finanças EPGE/FGV. E-mail: clovis.faro@fgv .br

${ }^{1}$ Tal denominação, que não costuma ser empregada em outros países, afigura-se como tendo origem no trabalho Observations on Reversionary Payments, de autoria de Price (1772), originalmente publicado em 1771, na Inglaterra. Veja-se Wikipédia, agosto de 2013, (http://pt.wikipedia.org/wiki/Richard-Price).
} 
presença de anatocismo. Tal é, exatamente, contrariamente ao entendimento de alguns autores, como Nogueira (2002) e De-Losso et alii (2013), o caso da Tabela Price; conquanto esteja implícito o regime de juros compostos, se não houver prestação em atraso, não há a ocorrência de anatocismo.

Como o assunto é objeto de polêmicas, não raras vezes têm sido promulgadas sentenças judiciais determinando que a amortização de financiamentos seja efetuada segundo os preceitos do regime de juros simples. Sendo que, em particular, usando uma denominação inadequada, tem ocorrido sentenças estipulando a adoção do que veio a ser chamado de "método de Gauss" (Durigan, 2013, - Advocacia). ${ }^{2}$

Nosso objetivo no presente artigo é o de, com fundamento em um arcabouço teórico que suporta o que iremos denominar de condições de consistência (financeira), analisar criticamente tanto as características da Tabela Price, como também as associadas a alguns sistemas de amortização, com prestações constantes, que fazem uso do regime de juros simples.

\section{ESTRUTURA ANALÍTICA}

Para nossas finalidades, iremos considerar a situação onde um financiamento de valor $F$, deve ser amortizado mediante o pagamento de $n$ prestações periódicas e postecipadas (isto é, com a primeira vencendo-se um período após a data de concessão do empréstimo), todas elas iguais ao valor constante $P$.

Ainda mais, considerada a taxa periódica de juros $i$, seja ela de juros simples ou de juros compostos, suposta positiva, admitiremos, como adiante formalizado, haver equivalência financeira entre o valor financiado $F$, e a sequência formada pelas $n$ prestações periódicas e iguais a $P$.

\subsection{Definições}

Define-se o total contábil de juros, que está embutido no financiamento e que será denotado por $\widehat{J}$, como:

$$
\widehat{J}=n \cdot P-F
$$

com $\widehat{J}>0$, posto que supomos i $>0$.

Por outro lado, podemos sempre admitir que cada prestação seja composta de duas parcelas. Uma, dita de amortização (ou de redução do valor do principal $F$ que foi financiado), e a outra, de juros (ou de remuneração pelo financiamento).

Denotando por $A_{k}$ a parcela de amortização que está contida na $k$-ésima prestação, e por $J_{k}$ a correspondente parcela de juros, temos que

$$
A_{k}+J_{k}=P, k=1,2, \ldots n
$$

com

$$
\sum_{k=1}^{n} A_{k}=F
$$

e

$$
\sum_{k=1}^{n} J_{k}=\widehat{J}=n \cdot P-F
$$

\footnotetext{
${ }^{2}$ É aí mencionada sentença dos autos 2000.70.00.023505-4, às fls 227/262, da Vara Federal Especializada do Sistema Financeiro da Habitação de Curitiba, condenando instituições financeiras a substituir a Tabela Price pelo "método linear ponderado - ou de Gauss".
} 


\subsection{Conceito de Consistência (Financeira)}

Diremos que um sistema de amortização de dívidas é (financeiramente) consistente, se, denotando por $S_{k}$ o saldo devedor (estado da dívida ou débito remanescente), logo após o pagamento da $k$-ésima prestação, para $k=1,2, \ldots, n$, o seu valor puder ser indistintamente determinado segundo qualquer um dos três seguintes procedimentos:

a) método retrospectivo - o que se deve é igual ao valor $F$ do financiamento, subtraído da soma das parcelas de amortização já efetuadas. Ou seja, formalmente, se:

$$
S_{k}=F-\sum_{\ell=1}^{k} A_{\ell}
$$

b) método prospectivo - o saldo devedor na época $k$, é igual ao valor atual (como adiante definido) e à taxa $i$ do financiamento, das $n-k$ prestações remanescentes.

c) método de recorrência - o que se deve na época $k$, é igual ao que se deveria se nada houvesse sido pago (o que corresponde ao valor $F$ financiado, acrescido de juros à taxa $i$, por $k$ períodos), deduzido do montante (como adiante explicitado), na época $k$ e à taxa $i$, das $k$ prestações já pagas.

Adicionalmente, o conceito de consistência (financeira), aqui enunciado, completa-se com a interpretação de que a $k$-ésima parcela de juros, $J_{k}$, deva ser igual aos juros, por um período e à taxa $i$, seja ela de juros simples ou de juros compostos, relativos ao saldo devedor na época $k-1$.

Ou seja, formalmente, se:

$$
J_{k}=i . S_{k-1}, k=1,2 \ldots, n, \text { com } S_{0} \equiv F
$$

Observe-se também que, partindo da relação (5), como

$$
S_{k-1}-S_{k}=A_{k}
$$

decorre da relação (4) que

$$
S_{k-1}-S_{k}=P-J_{k}
$$

ou, face à relação (6)

$$
S_{k}=(1+i) S_{k-1}-P, \quad k=1,2 \ldots, n
$$

Em palavras, a relação (7), que não depende de que a taxa $i$ seja de juros simples ou de juros compostos, pois que diz respeito a um único período, expressa o fato, como deveria ser de entendimento comum, de que o que se deve um período após a época $k-1$, é igual ao que se devia naquela época, acrescido de juros à taxa $i$, subtraído do pagamento da prestação que se venceu na época $k$.

Tendo presente o arcabouço teórico aqui apresentado, vejamos agora o que acontece quando se considera a taxa $i$ como de juros compostos ou como de juros simples. 


\section{O CASO DO REGIME DE JUROS COMPOSTOS (TABELA PRICE)}

Na eventualidade em que seja especificado que a taxa $i$ considerada é de juros compostos, o resultante sistema de prestações constantes reduz-se ao chamado método francês ou da Tabela Price. Sendo que, formalmente, a hipótese de equivalência financeira entre o valor $F$ do financiamento e a sequência das $n$ prestações iguais a $P$, quando se considera a data de concessão do financiamento, época zero, como data focal, ${ }^{3}$ se expressa como:

$$
F=\sum_{j=1}^{n} P(1+i)^{-j}
$$

do que decorre que

$$
P=i . F /\left\{1-(1+i)^{-n}\right\}
$$

Como

$$
J_{1}=i . F
$$

segue-se que

$$
A_{1}=P-J_{1}=i . F /\left\{(1+i)^{n}-1\right\}
$$

Por outro lado, considerando-se épocas $k$ e $k+1$, podemos escrever:

$$
P=A_{k}+J_{k}=A_{k}+i . S_{k-1}=A_{k}+i\left(F-\sum_{\ell=1}^{k-1} A_{\ell}\right)
$$

e

$$
P=A_{k+1}+J_{k+1}=A_{k+1}+i . S_{k}=A_{k+1}+i\left(F-\sum_{\ell=1}^{k} A_{\ell}\right)
$$

Logo, subtraindo-se membro a membro, vem:

$$
A_{k+1}=(1+i) A_{k}
$$

Ou seja, no sistema de prestações constantes no regime de juros compostos à taxa $i$, as parcelas de amortização evoluem segundo uma programação geométrica de razão $1+i$, e termo inicial dado pela relação (11).

Por conseguinte, de acordo com o método retrospectivo, ter-se-á:

$$
S_{k}=F-\left\{A_{1}-(1+i) A_{k}\right\} /\{1-(1+i)\}=A_{1}\left\{(1+i)^{k}-1 / i\right.
$$

ou, ainda

$$
S_{k}=F\left\{(1+i)^{n}-(1+i)^{k}\right\} /\left\{(1+i)^{n}-1\right\}
$$

\footnotetext{
${ }^{3} \mathrm{Na}$ realidade, como analiticamente mostrado em de (de Faro, 2006, pp. 58-59), a propriedade de cindibilidade do prazo, que se verifica no regime de juros compostos, implica que a relação (9) vale qualquer que seja a data focal.
} 
Por outro lado, considerando-se a determinação do saldo devedor pelos métodos prospectivo e de recorrência, tem-se, respectivamente, que:

$$
S_{k}=\sum_{j=k+1}^{n} P(1+i)^{k-j}=P\left\{1-(1+i)^{k-n}\right\} / i
$$

ou

$$
S_{k}=F\left\{1-(1+i)^{k-n}\right\} /\left\{1-(1+i)^{-n}\right\}
$$

e

$$
S_{k}=F(1+i)^{k}-\sum_{j=1}^{k} P(1+i)^{k-j}=F(1+i)^{k}-P\left\{(1+i)^{k}-1\right\} / i
$$

ou

$$
S_{k}=F\left\{(1+i)^{k}-\left[(1+i)^{k}-1\right] /\left[1-(1+i)^{-n}\right]\right\}
$$

Observando que a relação (14'), multiplicando-se o numerador e o denominador por $(1+i)^{n}$, reduzse à relação (13'), conclui-se, de imediato, que há consistência (financeira) entre os métodos retrospectivo e prospectivo.

Consequentemente, para constatar a total consistência (financeira) do sistema francês (Tabela Price), basta verificar se, por exemplo, os métodos de recorrência e prospectivo conduzem ao mesmo resultado para o saldo devedor $S_{k}$. Isto é, se as relações (14') e (15') conduzem ao mesmo resultado.

Isso é formalmente conseguido observando-se que a relação de equivalência financeira dada por (8), pode ser convenientemente reescrita como:

$$
F=\sum_{j-1}^{k} P(1+i)^{-j}+\sum_{j=k+1}^{n} P(1+i)^{-j}
$$

Portanto, multiplicando-se ambos os membros de (8') por $(1+i)^{k}$, constata-se, trivialmente, a consistência (financeira) entre os métodos prospectivo e de recorrência.

\section{O CASO DO REGIME DE JUROS SIMPLES}

Suponha-se agora que, como costuma ser frequente em decisões judiciais, a taxa $i$ considerada deva ser de juros simples. Como, no regime de juros simples, o prazo de aplicação é não cindível, a determinação do valor $P$ da sequência das $n$ prestações constantes, fica dependendo da escolha da chamada data focal. ${ }^{4}$

No que se segue, iremos considerar duas distintas possibilidades para a data focal. Respectivamente a época zero, que é a de concessão do empréstimo, e que se afigura como a mais lógica, e a época $n$, que é a de pagamento da última prestação e que costuma aparecer em sentenças judiciais.

\section{1. Época Zero como Data Focal}

Em princípio, em sendo especificada a época zero como data focal, a relação de equivalência financeira entre o valor $F$ do financiamento e a sequência formada pelas $n$ prestações periódicas e constantes, dependerá, ainda, de que seja adotado o que se denomina de desconto racional, ou que seja estipulado o chamado desconto comercial (ou bancário).

\footnotetext{
${ }^{4}$ Em língua portuguesa, tal idiossincrasia já havia sido observada em de Faro (1969, pg. 33).
} 


\subsubsection{Adotando-se o Desconto Racional}

Nesta eventualidade, denotando-se por $\bar{P}$ o resultante valor da prestação constante, a equação de equivalência financeira entre o principal $F$ e a sequência das $n$ prestações periódicas e iguais a $\bar{P}$, é escrita como:

$$
F=\sum_{j=1}^{n} \bar{P} /(1+i . j)
$$

Muito embora, computacionalmente, a determinação numérica de $\bar{P}$ seja uma tarefa trivial, a relação (16) é, à exceção do caso trivial onde $n=1$, de crescentemente trabalhosa solução analítica, em função de $n .^{5}$

Para evidenciar que a sistemática em questão não satisfaz nossa condição de consistência (financeira), lançaremos mão do expediente de um exemplo numérico; que denominaremos de exemplo padrão.

Seja o caso onde $F=100.000$ unidades de capital, a taxa $i$, de juros simples, é $2 \%$ por período, e o empréstimo deva ser liquidado mediante o pagamento de $n=5$ prestações periódicas e constantes. Do que decorre que $\bar{P}=21.184,90$ u.c.

Para que se evidencie a ausência de consistência (financeira), é suficente que se constate que os métodos prospectivo e de recorrência conduzem a distintos valores para o saldo devedor.

Por exemplo, no caso da ilustração numérica, considerando-se o estado da dívida logo após o pagamento da terceira prestação, tem-se:

a) segundo o método prospectivo

$$
S_{3}=\sum_{k=4}^{5} \frac{\bar{P}}{1+i(k-3)}=21.184,90\left\{\frac{1}{1 \times 0,02}+\frac{1}{1+2 \times 0,02}\right\}=41.139,61 \quad \text { u.c. }
$$

B) segundo o método de recorrência

$$
\begin{aligned}
& S_{3}=F(1+0,02 \times 3)-\sum_{j=1}^{3} \bar{P}\{1+0,02(3-j)\}=106.000-21.184,90(1,04+1,02+1) \\
= & 41.174,21 \quad \text { u.c. }
\end{aligned}
$$

\subsubsection{Adotando-se o Desconto Comercial}

Mantida a especificação da data zero como data focal para a equação que exprime a equivalência financeira entre o valor $F$ do financiamento, e a sequência das $n$ prestações constantes, que agora denotaremos por $\hat{P}$, uma outra possibilidade, ainda no regime de juros simples à taxa $i$, é a adoção do que se denomina de desconto comercial (ou bancário).

Nesta eventualidade, que costuma ser empregada pelos bancos comerciais, especialmente em empréstimos de curto prazo, tem-se a seguinte equação de equivalência financeira:

$$
F=\sum_{j=1}^{n} \hat{P}(1-i . j)
$$

\footnotetext{
${ }^{5}$ Enquanto que, para $n=1$ se tenha $\bar{P}=\mathrm{F}(1+\mathrm{i})$, para $n=6$ se tem

$\bar{P}=\mathrm{F}\left(1+21 i+175 i^{2}+735 i^{3}+1624 i^{4}+1764 i^{5}+720 i^{6}\right) /\left(6+105 i+700 i^{2}+2205 i^{3}+2348 i^{4}+1764 i^{5}\right)$.
} 
Observando que devemos ter satisfeita a condição de que se tenha $n<1 / i$, que pode ser entendida como a razão de que o desconto comercial só seja empregado em empréstimos de curto prazo, temos a seguinte solução analítica para a equação dada pela relação (17); solução esta que faz uso da soma dos $n$ primeiros números naturais, que é igual a :

$$
\hat{P}=2 F /\{n[2-i(n+1)]\}
$$

O que, no caso do exemplo padrão, implica em $\hat{P}=21.276,60$ u.c.

Quanto ao cálculo do saldo devedor, por exemplo, na época 3, de acordo com o método prospectivo, teríamos:

$$
S_{3}=\sum_{j=4}^{5} \hat{P}\{1-i(j-3)\}=21.276,60(1-0,02+1-0,02 \times 2)=41.276,60 \quad \text { u.c. }
$$

Sendo que, segundo o método de recorrência, o saldo devedor nessa mesma época 3, seria: ${ }^{6}$

$$
\begin{gathered}
S_{3}=F(1+3 i)-\sum_{j=1}^{3} \hat{P}\{1+i(3-j)\} \\
=100.000(1+3 \times 0,02)-21.276,60(1+0,02 \times 2+1+0,02 \times 1+1)=40.893,60 \text { u.c. }
\end{gathered}
$$

Por conseguinte, fica constatado que, também no caso de adoção de desconto comercial, não é satisfeito o critério de consistência (financeira). Isso, mesmo no caso, como o do exemplo, de um empréstimo de curto prazo. Sendo que, como $i=2 \%$ por período, os prazos devem ser (significativamente) inferiores a 50 períodos.

\section{2. Época do Último Pagamento como Data Focal}

Correntemente, visto que nossos tribunais repudiam o que se denomina de anatocismo, que, equivocadamente, como já anteriormente mencionado, costuma ser entendido como estando necessariamente presente no emprego da Tabela Price, tem sido proposto (Antonik e Assunção, 2006, Nogueira, 2013), que amortizações de dívidas por meio de prestações constantes, sejam efetuadas com base no regime de juros simples e adotando-se o final do prazo do financiamento como data focal; época $n$.

Tal implica em que a equação de equivalência financeira entre o valor $F$ do financiamento, e a sequência das $n$ prestações constantes, cujo valor agora denotaremos por $P^{*}$, considerada a taxa periódica $i$ de juros simples, seja escrita como:

$$
F(1+i . n)-\sum_{j=1}^{n} P^{*}\{1+i(n-j)\}
$$

Por oportuno, notemos que o resultante valor de $P^{*}$, dado por (20), costuma, aqui em terras brasílicas, ser dito estar sendo determinado de acordo com o "método de Gauss".?

\footnotetext{
${ }^{6}$ Note-se que, incongruentemente, enquanto valores atuais estão sendo calculados segundo os ditames do desconto comercial, valores futuros estão sendo determinados com base na relação clássica do regime de juros simples, $C_{n}=C_{0}(1+i . n)$. Entretanto, mesmo que valores futuros fossem calculados com base no entendimento de que se trataria de uma operação inversa à de desconto comercial, ou seja $N=V /(1-i . n)$, também seria constatada a inconsistência apontada. Posto que, com tal entendimento, o método de recorrência conduziria a $S_{3}=100.000 /(1-3 \times 0,02)-21.276,60\left\{(1-2 \times 0,01)^{-1}+\right.$ $\left.(1-0,02)^{-1}+1\right\}=41.232,44$, u.c.

${ }^{7}$ Para uma apresentação mais abrangente, incluindo comparações analíticas e numéricas dos valores de $P \bar{P} \hat{P}$ e $P^{*}$, veja-se de Faro (2013a).
} 


$$
P^{*}=2 F(1+i . n) /\{n[2+i(n-1)]\}
$$

No caso de nosso exemplo padrão, temos que $P^{*}=21.153,85 u$.c, sendo que, considerando-se o saldo devedor logo após o pagamento da terceira prestação, se tem:

a) segundo o método prospectivo

$$
S_{3}=\sum_{j=4}^{5} P^{*}\left\{\frac{1}{1+i(j-3)}\right\}=21.153,85\left\{\frac{1}{1+0,02}+\frac{1}{1+2 \times 0,02}\right\}=41.079,30 \text { u.c. }
$$

B) segundo o método de recorrência

$$
\begin{array}{r}
S_{3}=F(1+3 i)-\sum_{j=1}^{3} P^{*}\{1+(3-j) i\}=100.000(1+3 \times 0,02) \\
-21.153,85(1,04+1,02+1)=106.000-64.730,77=41.269,23 \quad \text { u.c. }
\end{array}
$$

Ou seja, temos também o colapso do conceito de consistência (financeira).

\section{CONCLUSÃO}

Nossos tribunais têm sido pródigos em promulgar sentenças condenando o emprego do regime de juros compostos na amortização de dívidas. Isso porque, equivocadamente, nossos juízes acreditam que qualquer sistema de amortização que se fundamente no regime de juros compostos, implica na ocorrência do que se denomina de anatocismo.

Em particular, abomina-se a chamada Tabela Price; determinando-se que o cálculo das prestações seja efetuado com base no regime de juros simples, mediante o emprego de uma variante nominada como "método de Gauss".

Fixando atenção no caso de prestações constantes, mostrou-se que qualquer das três variantes, fundamentadas no regime de juros simples, que foram aqui analisadas, não satisfazem condições básicas de consistência (financeira). Condições essas que são plenamente atendidas no caso da Tabela Price.

Ademais, com a exceção do caso do desconto comercial, as duas outras sistemáticas que se fundamentam no regime de juros simples, implicam em prestações constantes inferiores àquelas que, para os mesmos valores de taxa de juro e de prazo, se associam à Tabela Price. Como consequência, além de serem intrinsicamente inconsistentes, acarretando cálculos equivocados nas apurações de juros contábeis e de saldos devedores, implicam em que devedores se locupletem em detrimento de credores, quando sentenças judiciais determinam que a Tabela Price seja substituída por um deles, sem que se alterem prazos e taxas de juros.

Por outro lado, tais tipos de sentenças judiciais tendem a provocar um efeito perverso. Buscando precaverem-se das perdas que estariam sendo impostas, as instituições financeiras lançariam mão do expediente de, preventivamente, aumentar as taxas de juros especificadas nos contratos de financiamento. 


\section{BIBLIOGRAFIA}

Antonik, L. \& Assunção, M. (2006). Tabela Price e Anatocismo. Revista de Administração da UNIMEP, 4(1):120-136.

de Faro, C. (1969). Matemática Financeira. APEC.

de Faro, C. (2006). Fundamentos da Matemática Financeira. Saraiva.

de Faro, C. (2013a). Amortização de Dívidas e Prestações Constantes: uma Análise Crítica. Ensaio Econômico da EPGE, 746.

de Faro, C. (2013b). Uma Nota Sobre Amortização de Dívidas: Juros Compostos e Anatocismo. Revista Brasileira de Economia, 67(3):283-295.

de Faro, C. \& Guerra, S. (2009). Anatocismo: o Direito (a Justiça) e a Matemática Financeira. Revista de Direito do Tribunal de Justiça do Estado do Rio de Janeiro, 80:120-129.

De-Losso, R., Giovannetti, B., \& Rangel, A. (2013). Sistema de Amortização por Múltiplos Contratos: a Falácia do Sistema Francês. Economic Analysis of Law Review, 4(1):160-180.

Durigan, P.-A. (2013). SFH, Sistema Price, Anatocismo e Método de Gauss. http://www.paulo.durigan.com.br/content/sfh-sistema-pr.

Houaiss, A. (2001). Dicionário Houaiss da Língua Portuguesa. Objetiva.

Nogueira, J. (2002). Tabela Price: da prova documental e precisa do seu anatocismo. Servanda.

Nogueira, J. M. (2013). Tabela Price: Mitos e Paradigmas, $3^{\mathrm{a}}$ Ed. Millenium.

Price, R. (1772). Observations on Reversionary Payments, 2nd Ed. Cadell. 